\title{
Trends in pre-military sexually transmitted infections and associated risk behaviours in Canadian Armed Forces recruits
}

\author{
Heather McCuaig Edge ${ }^{1 *}$
}

\begin{abstract}
Background: Sexually transmitted infections (STIs) have historically been problematic for militaries. Recent reports indicating that rates of STIs among young male Canadian Armed Forces (CAF) members are higher than civilians prompted a need to better understand CAF members' reported rates of STIs and their behavioural risk factors for STIs. This study examined the prevalence of self-reported pre-military sexual behaviours (i.e. number of sexual partners and frequency of condom use) and history of a STI diagnosis among CAF recruits attending basic military training using data collected from the Recruit Health Questionnaire.

Methods: Data came from 50,603 recruits who participated in the survey between 2003 and 2018 (84.9\% male, 78.6\% Non-Commissioned Member candidates, $64.9 \%$ aged between 17 and 24 years).
\end{abstract}

Results: Among sexually active recruits, the proportions who had more than one sexual partner in the previous year increased from $30.5 \%$ in $2003(95 \% \mathrm{Cl}, 27.8-33.4)$ to $35.5 \%$ in 2018 (95\% $\mathrm{Cl}, 34.0-37.0)$. Of recruits who were not in an exclusive relationship at the time, the proportions who reported always using a condom decreased from $50.8 \%$ in $2003(95 \% \mathrm{Cl}, 46.4-55.1)$ to $40.2 \%$ in 2018 (95\% Cl, 38.3-42.2). Overall, 5.5\% (95\% Cl, 5.3-5.7) reported ever having received a STI diagnosis. Demographic differences by age and sex were also found.

Conclusion: These observations provide an indication of the baseline, pre-enlistment STI risk behaviours, and STI history among CAF recruits, and may provide insight into avenues for targeted interventions and health promotion programming, such as education and screening initiatives.
This work is licensed under a Creative Commons Attribution 4.0 International License.

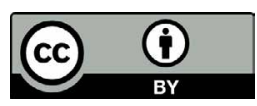

Affiliation

1 Directorate Force Health Protection, Canadian Forces Health Services and Directorate Research Personnel and Family Support, Department of National Defence, Ottawa, ON

*Correspondence: heather. mccuaigedge@forces.gc.ca

Suggested citation: McCuaig Edge HJ. Trends in pre-military sexually transmitted infections and associated risk behaviours in Canadian Armed Forces recruits. Can Commun Dis Rep 2020;46(9):272-78.

https://doi.org/10.14745/ccdr.v46i09a04

Keywords: sexually transmitted infections, Canadian Armed Forces, military recruits, risk behaviours, condom use, number of sexual partners

\section{Introduction}

Sexually transmitted infections (STIs) have historically been problematic for militaries (1,2). For example, reported rates of STIs have been much higher in the United States (US) military population compared with the civilian population (3-5). Recent comparisons between the Canadian general population (CGP) and Canadian Armed Forces (CAF) personnel revealed that while rates of STIs were the same as or lower than civilians in most demographic groups, the rates of STIs among young (i.e. younger than 30 years) male CAF members were almost double those of their civilian counterparts (6). A qualitative study revealed that CAF personnel and healthcare providers alike perceived STIs as a problem within CAF, and many indicated that STIs were similarly, or even more, problematic for CAF than for the CGP (7).

The Public Health Agency of Canada has identified behavioural risk factors associated with STIs; including sexual activity in youth younger than 25 years, new or more than two sexual partners in the previous year, unprotected sex, alcohol or substance use and a history of a STI, among others (8). Military members may be at elevated risk for acquiring STIs given the younger age of the majority of personnel, frequent and extended time spent away 
from home for training or operations, deployments to areas with higher rates of STls, or elevated rates of risk-taking attitudes and behaviours associated with STIs (9-11). Self-reported STI risk behaviours among serving CAF members indicated that almost $21 \%$ reported having had two or more sexual partners in the previous 12 months, and of those, only $22 \%$ reported always using a condom, while approximately $18 \%$ reported never using a condom (12).

Determining the baseline prevalence and demographic profiles of STI risk behaviours and STI history among new recruits can inform education, screening and intervention practices at the beginning of the military career. Thus, this study examined the prevalence of STI risk behaviours (i.e. number of sexual partners and frequency of condom use) and self-reported pre-military history of a STI diagnosis among CAF recruits attending basic military training (BMT).

\section{Methods}

Data for this study were collected between July 2003 and December 2018 using the Recruit Health Questionnaire (RHQ), administered during the first few weeks of BMT at the Canadian Forces Leadership and Recruit School in St-Jean-sur-Richelieu, Québec. All Regular Force Non-Commissioned Member (NCM) and Officer candidates (hereafter collectively referred to as "recruits") enrolled in BMT were invited to complete the RHQ-a long term, ongoing surveillance study that provides baseline health and lifestyle information about recruits. The $\mathrm{RHO}$ is a voluntary survey that recruits provide written consent to participate in. Participants' data is linked via service number to health data collected later in their career; thus, data are confidential, not anonymous. Approximately $75 \%$ of recruits completed the RHQ. The RHQ study protocol was approved by the Defence Research and Development Canada Human Research Ethics Committee.

The RHQ includes items assessing number of sexual partners in the previous year, frequency of condom use and STI history. Number of sexual partners was assessed with the question "How many different sexual partners have you had in the past 12 months?" with response options of "none," "one partner," "two partners," "three partners" or "four or more". Frequency of condom use was assessed with the question, "If you were not in an exclusive relationship at the time, how often did you use a condom in the past 12 months?" with response options of "always," "usually," "occasionally," "never" and "not applicable". The proportion of respondents with a previous STI diagnosis were estimated based on "yes/no" responses to the question, "Have you ever been told by a doctor or nurse that you had a sexually transmitted infection-like chlamydia, gonorrhea, genital herpes, or syphilis?" The procedure of administration and questions related to sexual behaviours and STI history has not changed over the 16-year period.
The data about sexual behaviours and STI history are self-reported and are, thus, subject to recall and social desirability biases, which may result in under or over-reporting (13). As noted elsewhere (14), while the impact of social desirability on self-reports of sexual behaviours is difficult to quantify, studies have confirmed the general reliability of responses.

Descriptive analysis of crude proportions along with $95 \% \mathrm{Cls}$ was examined for each cohort year. Sequential logistic regressions controlling for age and sex were conducted to identify linear and non-linear (i.e. quadratic or cubic) trends over time, with cohort year (or its squared or cubed value) entered as a continuous variable. A trend was detected if the addition of cohort year (or its squared or cubic values) to the model significantly improved the model fit, as indicated by a significant chi-square. Difference tests between cohort years were conducted using z-tests of proportions, while chi-square analyses were conducted to detect demographic differences.

\section{Results}

Data were available for 50,603 cases from recruits who participated in the RHQ between July 2003 and December 2018. Respondents were mostly male (84.9\%), NCM candidates (78.6\%), primarily English-speaking (72.7\%) and between 17 and 24 years old when they completed the RHO (64.9\%; $M=24.0$; $S D=5.9$ ).

\section{Trends, 2003-2018}

Among sexually active recruits, the proportions who had two or more sexual partners in the previous year increased from $30.5 \%$ overall in $2003(95 \% \mathrm{Cl}, 27.8-33.4)$ to $35.5 \%$ overall in 2018 (95\% Cl, 34.0-37.0; $p<0.01$; Figure 1). Significant trends, controlling for age and sex, indicated that the number of sexual partners reported by recruits in the previous year have fluctuated between 2003 and $2018\left(\chi^{2}(5)=1,344.28 ; p<0.001\right)$.

Of recruits who were not in an exclusive relationship at the time, the proportion who reported always using a condom decreased from $50.8 \%$ in $2003(95 \% \mathrm{Cl}, 46.4-55.1)$ to $40.2 \%$ in 2018 (95\% Cl, 38.3-42.2; $p<0.001$; data not shown). As depicted in Figure 2, the proportion who reported never using a condom increased from 16.5\% in $2003(95 \% \mathrm{Cl}, 13.5-20.0)$ to $25.7 \%$ in 2018 (95\% Cl, 24.0-27.5; $p<0.001$ ). Respondents who selected "not applicable" were excluded from these analyses, resulting in a reduced $n=27,783$ for this STI risk behaviour. Significant trends controlling for age and sex were found, indicating that rates of condom use reported by recruits during the previous year have varied significantly over the 16 -year period $\left(\chi^{2}(5)=400.70\right.$; $p<0.001)$.

Overall, 5.5\% (95\% Cl, 5.3-5.7) of recruits reported ever having received a STI diagnosis (Figure 3 ). These proportions were not significantly different for the 2003 or 2018 recruit cohorts. 
Figure 1: Annual overall and sex-specific rates of self-reported number of sexual partners in Canadian Armed Forces recruits, two or more partners in the previous year, 2003-2018

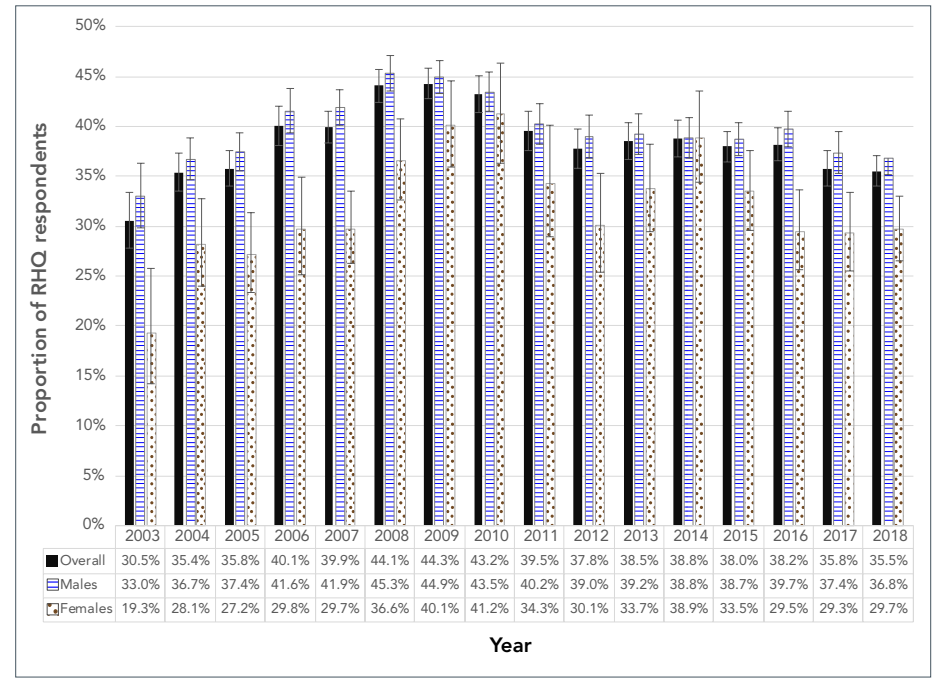

Abbreviation: $\mathrm{RHQ}$, Recruit Health Questionnaire

Figure 3: Annual overall and sex-specific rates of self-reported history of sexual transmitted infections diagnosis in Canadian Armed Forces recruits, 2003-2018

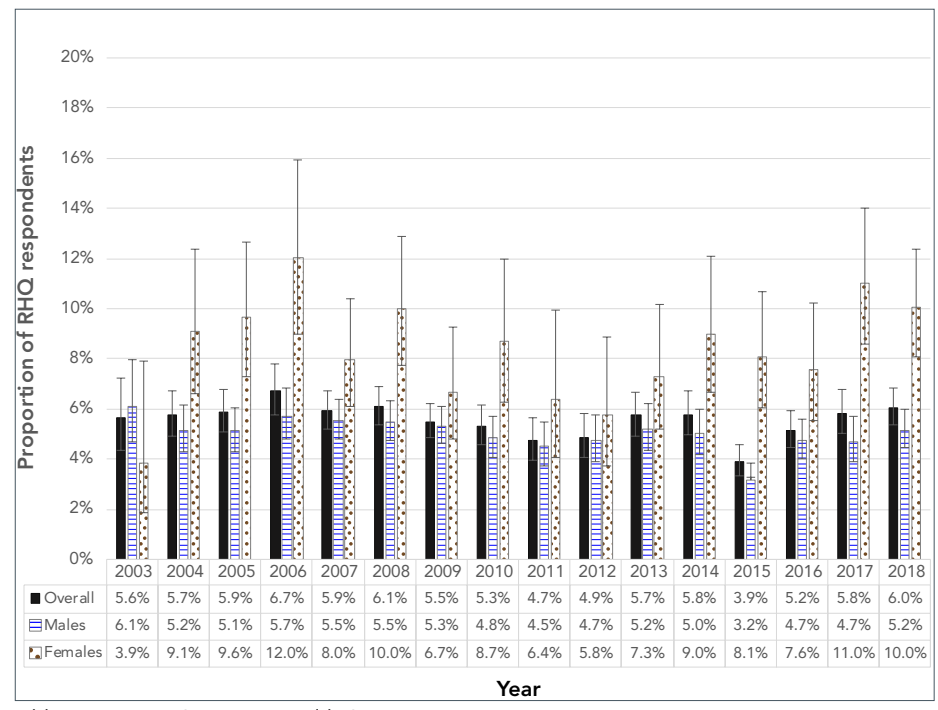

Abbreviation: RHQ, Recruit Health Questionnaire

There was a significant trend found in the rates of recruits having reported ever having had a STI diagnosis $\left(\chi^{2}(5)=445.18\right.$; $p<0.001$ ) after controlling for age and sex, indicating that the rates of reported STI diagnoses varied over the 16-year period.

\section{Demographic differences}

Pooling responses over the 16-year period, demographic differences by sex and age were also found for number of sexual partners, condom use and STI history. As depicted in Figure 4, more male than female recruits reported having two or more
Figure 2: Annual overall and sex-specific rates of self-reported rates of never using a condom in the previous year, for Canadian Armed Forces recruits not in a relationship, 2003-2018

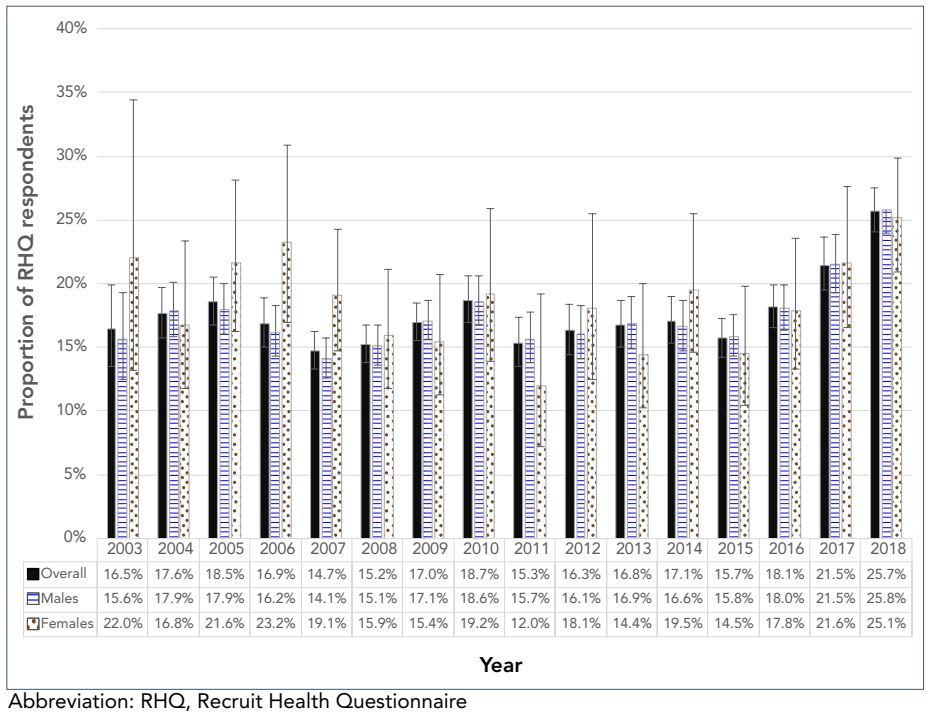

sexual partners in the previous year $\left(\chi^{2}(2)=716.75 ; p<0.001\right)$, while more female than male recruits reported a previous STI diagnosis $\left(\chi^{2}(1)=43.44 ; p<0.001\right)$. Of recruits who were not in an exclusive relationship at the time, more female than male recruits reported always using a condom (data not shown; $\chi^{2}(2)=84.93$; $p<0.001$ ); however, there were no differences in the proportions of male and female recruits who reported never using a condom.

Figure 4: Sexually transmitted infections history and associated risk behaviours in Canadian Armed Forces recruits, by sex

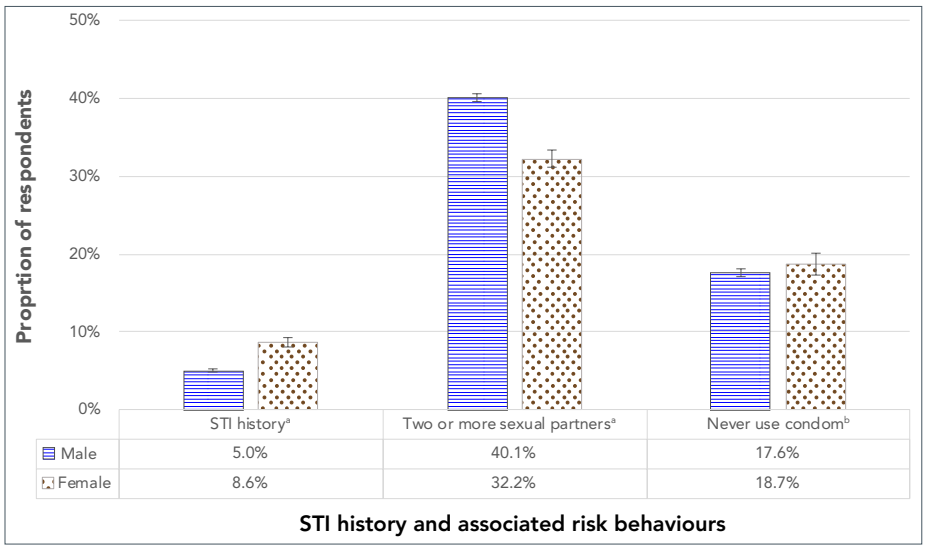

Abbreviation: STI, sexually transmitted infection

a $p<0.001$

$\mathrm{b}$ not significant

As depicted in Figure 5, the proportions of reports of having two or more sexual partners in the previous year significantly differed for each age group $\left(x^{2}(6)=3,183.48 ; p<0.001\right)$, with the highest proportion among recruits aged 20 to 24 years. Recruits aged 30 or older who were not in an exclusive relationship had the highest proportion of reports that they never used a condom, 
with the proportions being significantly lower in each descending age group $\left(\chi^{2}(6)=365.01 ; p<0.001\right)$. There were proportionally more recruits aged 25 or older who reported a history of a STI diagnosis than younger recruits $\left(x^{2}(3)=512.67 ; p<0.001\right)$, with the youngest group of recruits (i.e. those aged 17 to 19 years) reporting the lowest proportion of STI diagnosis history.

\section{Figure 5: Sexually transmitted infections history and associated risk behaviours by age group in Canadian Armed Forces recruits}

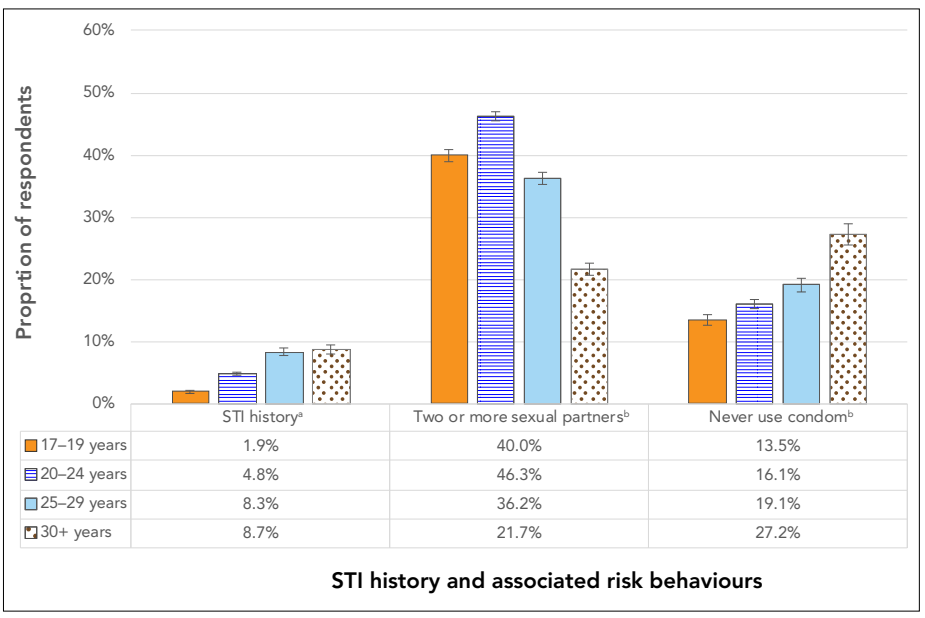

Abbreviation: STI, sexually transmitted infection

The first three columns are $p<0.001$, the first, second, and fourth columns are $p<0.001$, and the third and fourth columns are not significant ${ }^{\mathrm{b}} \mathrm{p}<0.001$

\section{Discussion}

Observations from the RHO concerning the number of sexual partners, frequency of condom use and STI history, suggest that the majority of recruits were not engaging in risky sexual behaviours. However, at least a third of recruits reported having had two or more sexual partners in the year prior to starting BMT. More recently, among those who were not in an exclusive relationship at the time, a quarter of recruits reported never using a condom. From 2003 to 2018, the proportions of recruits reporting multiple sexual partners and never wearing a condom increased. These patterns in STI risk behaviours mirror the recent increases in rates of STls reported in the general population in Canada (15-17) and in other high-income countries $(18,19)$, and are also consistent with increased risky sexual behaviours among adolescents and adults in the CGP $(14,20,22)$.

While reports of recruits having had a STI diagnosis prior to BMT have remained relatively low, consistently more female than male recruits reported a history of STI diagnosis. This is unsurprising given that, for certain STIs (e.g. chlamydia), women tend to have higher rates of infection than men (16) and tend to be screened and/or seek health care more regularly, and would, therefore, be more likely to have been diagnosed than men (23-25). Moreover, because of their physiology, women are more susceptible than men to acquire STIs (24).
Differences in the number of sexual partners between men and women were consistent with findings that men tend to report having more sexual partners than women $(14,21,22)$. This difference may be due to socialization, gender roles or sociocultural norms surrounding sexual behaviours and the reporting thereof (26). In line with findings from the CGP $(21,22)$, the proportion of recruits reporting multiple partners was lower in the older age groups, possibly due to increased likelihood of older recruits being in longer term, monogamous relationships. The largest proportion of recruits reporting multiple partners was among the 20 to 24-year old group, which is the age group with the highest rates of gonorrhea (17) and chlamydia (16) and the third highest rates of infectious syphilis in the CGP in 2015 (15).

Consistent with findings from the CGP that have found that regular condom use declines with age $(14,20,23)$, a higher proportion of older recruits who were not in an exclusive relationship at the time reported never using a condom, compared with younger recruits. This could be due to the increased use of other contraceptive methods for preventing pregnancy with increased age (21); however, these methods do not prevent STIs.

Findings from recruits are consistent with the rates and behaviours found in the CGP; this is unsurprising since recruits were drawn from the CGP and had not yet begun their military careers when the RHQ was administered. The importance of this research for CAF in its efforts to prevent STIs are highlighted by the observed increasing rates of STI risk behaviours, the higher STI rates and risk among military members $(3-6,9,27)$ and perceptions of STIs as a problem for CAF (7). These efforts may be especially important for recruits, who have not yet experienced some of the military situations that may place military personnel at increased risk for acquiring STIs, such as deployments $(9,11)$, or having higher levels of risk propensity (28). While the risk for STIs may be elevated for military members, CAF also presents an opportunity for members to more easily access health care for primary and secondary prevention and health promotion programming. Other militaries have implemented programs that have reduced STI rates, such as in US recruit training centers, and have proven effective at increasing STI knowledge and perceived norms for safe sex (29-33). These programs included mass screening and programming that included presentations and activities to educate about the transmission, symptoms and prevention of STIs, or emphasized adaptive decision-making skills and communication strategies. Other programs aimed at the general population using digital interventions, online programs and social media have been effective at increasing condom use, knowledge and perceived norms surrounding safe sex, especially among younger individuals (34-36). Similar programming and interventions could be implemented in CAF's BMT program or in other routine training or health promotion activities throughout the military career. 


\section{Strengths and limitations}

This surveillance report, based on observational data, presents a baseline indication of pre-enlistment STI risk behaviours and STI history among recruits. It provides trend information for 16 years of recruit cohorts, and describes demographic differences in reports of STI history, number of sexual partners in the previous 12 months and frequency of condom use. These findings underscore the rising trends in risky behaviours associated with acquiring STIs in both the CGP and in CAF recruits, as well as provide insight into demographic information about groups of individuals at particular risk for STIs. These data could inform the development of screening tools to identify segments of the recruit population that might benefit from targeted interventions and health promotion programming.

This study and the RHQ are not without limitations. The RHQ data were self-reported; a technique which is prone to social desirability bias, recall bias and subjectivity $(13,37)$. In addition, there was no way of assessing the accuracy of responses. Further, we had single item measures asking about sensitive topics. As such, some recruits may have been reluctant to disclose personal information about their sexual history and sexual behaviours, which may have resulted in under-reporting. The requirement for an individual to be in an "exclusive relationship" in the question about frequency of condom use may have resulted in the exclusion of individuals who had been in serially monogamous relationships. These individuals may not have responded, as they considered themselves to be in an "exclusive relationship", yet the nature of these relationships may expose them to a significant number of sexual partners in a short period of time. Moreover, the current $\mathrm{RHO}$ does not consider sexual identity or sexual preference, which may impact risk behaviours for STIs and intervention strategies. Future research on STI risk behaviours with CAF members should take sexual preference into consideration. Finally, the RHQ is voluntary, so results are based on the subset of recruits who chose to respond rather than the whole population of recruits who trained during this period. Although the overall response rate was high (75.6\%), there may be demographic differences between respondents and nonrespondents.

\section{Conclusion}

Since 2003, risk behaviours for acquiring STIs have increased among recruits, but these rates are consistent with similar increases observed in CGP. Findings from this study provide baseline information about sexual risk behaviours for STls among CAF population, and a demographic profile of those at higher risk for STIs. These findings may provide insight, especially for CAF, into avenues for targeted interventions and health promotion programming, such as education, primary and secondary prevention and screening initiatives.

\section{Author's statement}

HJME conceived and wrote the article.

\section{Competing interests}

None.

\section{Acknowledgements}

The author would like to thank the following members of the Canadian Forces Health Services Group and Director General Military Personnel and Analysis for their valuable help and feedback on this article: Dr. D Lu; Cdr K Barnes; Dr. J Lee; G Ivey; S Carlucci; LCol C Rossi and Col P Morissette.

\section{Funding}

This project was funded by the Department of National Defence, Canada.

\section{References}

1. Gaydos CA, Quinn TC, Gaydos JC. The challenge of sexually transmitted diseases for the military: what has changed? Clin Infect Dis 2000;30(4):719-22. DOI PubMed

2. Rasnake MS, Conger NG, McAllister K, Holmes KK, Tramont EC. History of U.S. military contributions to the study of sexually transmitted diseases. Mil Med 2005;170(4S):61-5. DOI PubMed

3. Aldous WK, Robertson JL, Robinson BJ, Hatcher CL, Hospenthal DR, Conger NG, Murray CK. Rates of gonorrhea and Chlamydia in U.S. military personnel deployed to Iraq and Afghanistan (2004-2009). Mil Med 2011;176(6):705-10. DOI PubMed

4. Jordan NN, Lee SE, Nowak G, Johns NM, Gaydos JC. Chlamydia trachomatis reported among U.S. active duty service members, 2000-2008. Mil Med 2011;176(3):312-9. DOI PubMed

5. Seña AC, Miller WC, Hoffman IF, Chakraborty H, Cohen MS, Jenkins P, McKee KT Jr. Trends of gonorrhea and chlamydial infection during 1985-1996 among active-duty soldiers at a United States Army installation. Clin Infect Dis 2000;30(4):742-8. DOI PubMed

6. Directorate of Force Health Protection. Communicable Disease Database. Ottawa (ON): DND; 2018.

7. Lee JE, Watkins K, Crane F, Schofield S, Tepper M. Perceptions of risk and testing for sexually transmitted infections among military personnel and health care providers in the Canadian Armed Forces: A qualitative study. Mil Behav Health 2015;3(1):37-46. DOI 
8. Public Health Agency of Canada. Section 2: Canadian Guidelines on Sexually Transmitted Infections - Primary Care and Sexually Transmitted Infections. Ottawa (ON): PHAC; 2013. https://www.canada.ca/en/public-health/services/ infectious-diseases/sexual-health-sexually-transmittedinfections/canadian-guidelines/sexually-transmittedinfections/canadian-guidelines-sexually-transmittedinfections-17.html

9. Shafer MA, Boyer CB, Shaffer RA, Schachter J, Ito SI, Brodine SK. Correlates of sexually transmitted diseases in a young male deployed military population. Mil Med 2002;167(6):496-500. DOI PubMed

10. Leigh BC. Peril, chance, adventure: concepts of risk, alcohol use and risky behavior in young adults. Addiction 1999 Mar;94(3):371-83. DOI PubMed

11. Korzeniewski K. Sexually transmitted infections among army personnel in the military environment. In: Malla N, editor. Sexually Transmitted Infections. Rijeka, Croatia: InTech; 2012. p. 165-82.

12. Born JA, Bogaert L, Payne E, Wiens M. Results from Health and Lifestyle Information Survey of Canadian Forces Personnel 2008/2009 - Regular Force Version. Ottawa (ON): DND; 2010. http://publications.gc.ca/site/eng/410267/ publication.html

13. Fenton KA, Johnson AM, McManus S, Erens B. Measuring sexual behaviour: methodological challenges in survey research. Sex Transm Infect 2001;77(2):84-92. DOI PubMed

14. Rotermann M. Sexual behaviour and condom use of 15- to 24-year-olds in 2003 and 2009/2010. Health Rep 2012;23(1):41-5. DOI PubMed

15. Choudhri Y, Miller J, Sandhu J, Leon A, Aho J. Infectious and congenital syphilis in Canada, 2010-2015. Can Commun Dis Rep 2018;44(2):43-8. DOI PubMed

16. Choudhri Y, Miller J, Sandhu J, Leon A, Aho J. Chlamydia in Canada, 2010-2015. Can Commun Dis Rep 2018;44(2):4954. DOI PubMed

17. Choudhri Y, Miller J, Sandhu J, Leon A, Aho J. Gonorrhea in Canada, 2010-2015. Can Commun Dis Rep 2018;44(2):37-42. DOI PubMed

18. Public Health England. Sexually transmitted infections and screening for chlamydia in England, 2018. Health Protection Report. London (UK): Public Health England; 2019. https:// assets.publishing.service.gov.uk/government/uploads/ system/uploads/attachment_data/file/806118/hpr1919_ stis-ncsp_ann18.pdf

19. The Kirby Institute. HIV, viral hepatitis and sexually transmissible infections in Australia: Annual surveillance report 2017. Sydney (AU): Kirby Institute, University of New South Wales; 2017. https://kirby.unsw.edu.au/sites/default/ files/kirby/report/SERP_Annual-Surveillance-Report-2017_ compressed.pdf
20. McKay A, Milhausen R, Quinn-Nilas MA. Preliminary report: Sexually transmitted infection (STI) risk among single adults in the Trojan/SIECCAN Sexual Health at Midlife Study. Toronto (ON): SIECCAN; 2016. http://sieccan.org/ wp-content/uploads/2018/05/Trojan-SIECCAN-STI-report. pdf

21. Milhausen RR, McKay A, Graham CA, Crosby RA, Yarber WL, Sanders SA. Prevalence and predictors of condom use in a national sample of Canadian university students. Can J Hum Sex 2013;22(3):142-51. DOI

22. Rotermann M, McKay A. Condom use at last sexual intercourse among unmarried, not living common-law 20- to 34-year-old Canadian young adults. Can J Hum Sex 2009;18(3):75-87. https://www.macleans.ca/wp-content/ uploads/2009/09/condomusecjhs18309fin.pdf

23. Knight R, Falasinnu T, Oliffe JL, Gilbert M, Small W, Goldenberg S, Shoveller J. Integrating gender and sex to unpack trends in sexually transmitted infection surveillance data in British Columbia, Canada: an ethno-epidemiological study. BMJ Open 2016;6(8 e011209):e011209. DOI PubMed

24. Wong T, Singh A, Mann J, Hansen L, McMahon S. Gender differences in bacterial STIs in Canada. BMC Womens Health 2004;4 Suppl 1:S26. DOI PubMed

25. Thompson AE, Anisimowicz Y, Miedema B, Hogg W, Wodchis WP, Aubrey-Bassler K. The influence of gender and other patient characteristics on health care-seeking behaviour: a QUALICOPC study. BMC Fam Pract 2016;17:38. DOI PubMed

26. Mitchell KR, Mercer $\mathrm{CH}$, Prah P, Clifton S, Tanton C, Wellings K, Copas A. Why do men report more opposite-sex sexual partners than women? Analysis of the gender discrepancy in a British national probability survey. J Sex Res 2019;56(1):1-8. DOI PubMed

27. Russak SM, Ortiz DJ, Galvan FH, Bing EG. Protecting our militaries: a systematic literature review of military human immunodeficiency virus/acquired immunodeficiency syndrome prevention programs worldwide. Mil Med 2005;170(10):886-97. DOl PubMed

28. McCuaig Edge HJ, Beswick-Escanlar V. Risk propensity and risk factors for sexually transmitted infections in Canadian Armed Forces recruits. Mil Behav Health 2020;09. DOI

29. Arcari CM, Gaydos JC, Howell MR, McKee KT, Gaydos CA. Feasibility and short-term impact of linked education and urine screening interventions for Chlamydia and gonorrhea in male army recruits. Sex Transm Dis 2004;31(7):443-7. DOI PubMed

30. Boyer CB, Shafer MA, Shaffer RA, Brodine SK, Ito SI, Yniguez DL, Benas DM, Schachter J. Prevention of sexually transmitted diseases and HIV in young military men: evaluation of a cognitive-behavioral skills-building intervention. Sex Transm Dis 2001;28(6):349-55. DOI PubMed 
31. Booth-Kewley S, Minagawa RY, Shaffer RA, Brodine SK. A behavioral intervention to prevent sexually transmitted diseases/human immunodeficiency virus in a Marine Corps sample. Mil Med 2002;167(2):145-50. DOI PubMed

32. Jenkins PR, Jenkins RA, Nannis ED, McKee KT Jr, Temoshok LR. Reducing risk of sexually transmitted disease (STD) and human immunodeficiency virus infection in a military STD clinic: evaluation of a randomized preventive intervention trial. Clin Infect Dis 2000;30(4):730-5. DOI PubMed

33. Sánchez JL, Agan BK, Tsai AY, Macalino GE, Wurapa E, Mbuchi M, Dueger E, Horton KC, Montano-Torres SM, Tilley DH, Saylors KE, Puplampu N, Duplessis CC, Harrison DJ, Putnam SD, Garges EC, Espinosa BJ, Dejli J, Meyers M, Yingst SL, Jerse AE, Maktabi HH, Burke RL, Jordan NN, Nowak G, Hsu K, Soge OO, Holmes KK, McClelland RS, MacDonald MR, Pavlin JA, Gaydos JC, Tramont EC. Expanded sexually transmitted infection surveillance efforts in the United States military: a time for action. Mil Med 2013;178(12):1271-80. DOI PubMed
34. Mevissen FE, Ruiter RA, Meertens RM, Zimbile F, Schaalma HP. Justify your love: testing an online STI-risk communication intervention designed to promote condom use and STI-testing. Psychol Health 2011;26(2):205-21. DOI PubMed

35. Bull SS, Levine DK, Black SR, Schmiege SJ, Santelli J. Social media-delivered sexual health intervention: a cluster randomized controlled trial. Am J Prev Med 2012;43(5):467-74. DOI PubMed

36. Widman L, Nesi J, Kamke K, Choukas-Bradley S, Stewart JL. Technology-based interventions to reduce sexually transmitted infections and unintended pregnancy among youth. J Adolesc Health 2018;62(6):651-60. DOI PubMed

37. Fikretoglu D, D'Agata M, Blackler K, Liu A, McCuaig Edge H, Gottschall S, Blais AR. Social desirability effects in health research with Canadian Armed Forces recruits (DRDC-RDDC-2016-L324). Toronto (ON): Defence Research and Development Canada; 2016.

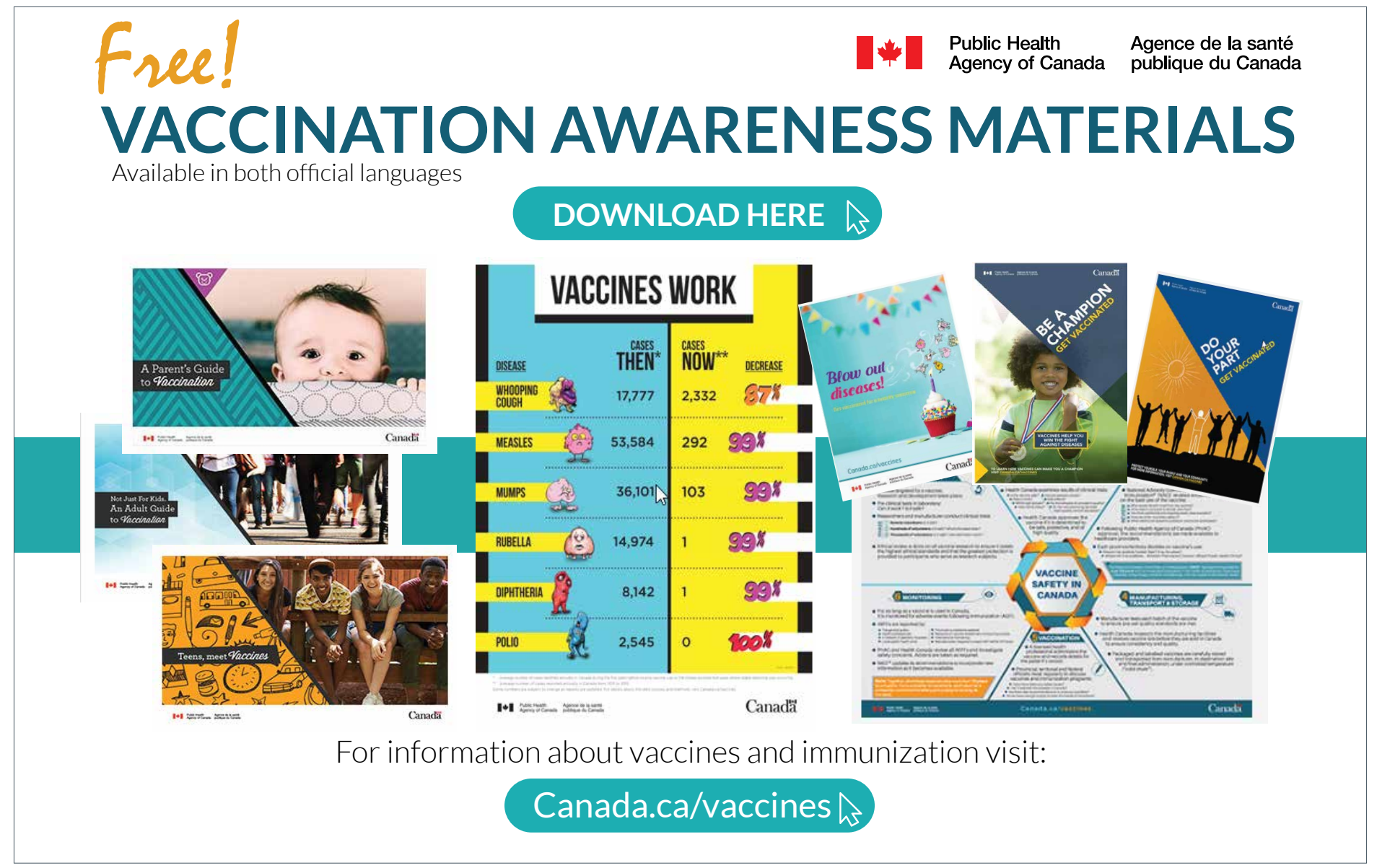

